\title{
Thermographical Analysis of Continuing Tradition of Mirror Casting in Kerala
}

\author{
Takekazu NAGAE, ${ }^{1) *}$ Sharada SRINIVASAN ${ }^{2)}$ Srinivasa RANGANATHAN ${ }^{2)}$ R. M. PILLAI, ${ }^{3)}$ Yasuji SHIMIZU ${ }^{4)}$ \\ and Haruhisa MIFUNE ${ }^{1)}$
}

1) University of Toyama, Japan.

2) National Institute of Advanced Studies, Bangalore, India.

3) John Cox

Memorial CSI Institute of Technology, Thiruvananthapuram, India.

4) Archaeological Institute of Kashihara, Nara, Japan.

(Received on November 30, 2013; accepted on March 3, 2014)

\begin{abstract}
Additions of large amounts of tin to copper lead to high tin bronzes with interesting combination of properties. Such high tin bronzes need to be carefully processed to avoid brittleness in compositions corresponding to beta and delta phases. The latter has been used in China, India, Korea and Japan to produce distortion free mirror images.

This investigation is concerned with the bronze mirror from India where the tradition has survived in the village Aranmula in Kerala. The alloy has an exceptionally high tin content consisting almost entirely of the delta phase, which is an intermetallic compound $\left(\mathrm{Cu}_{31} \mathrm{Sn}_{8}\right)$ of composition $32.6 \%$ tin. This is an ideal alloy to be polished into a mirror due to the silvery white color and high hardness. Its high brittleness is offset by an ingenious casting and polishing process.

In addition to studying the composition and the casting involving a mould cum crucible method, thermographic analysis has been employed to follow the solidification sequence by looking at the thermal profile. It is correlated with the actual composition, processing parameters and the resultant microstructure, due to the cooling rate the alloy solidifies with a mild departure from the equilibrium phase diagram. Some observations regarding the structure of the delta phase which is a Hume-Rothery phase will be provided about its optical and mechanical properties.
\end{abstract}

KEY WORDS: bronze mirror; Aranmula; thermographic analysis.

\section{Introduction}

Mirrors had both aesthetic value and religious significance in parts of Asia, as in China and India. Bronze mirrors with figurines on handles are known from ancient Egypt. Flat, circular tanged mirrors were found from Harappan contexts northwest of the Indian subcontinent at Quetta and Harappa in Pakistan (ca. 2000 BCE) and Dholavira in Gujarat, India. These would probably have been made of bronze of low tin content (i.e. $<10 \%$ tin).

India, China, Korea and Japan have long traditions in this bronze mirror alloy. It will be useful to make a comparison of the four nations to see any influence across space and time.

Since the early 1990s metallurgical and ethno- archaeological studies made by Indian scholars ${ }^{1-7)}$ on South Asian bronzes have documented the existence of high-tin bronzes from a range of contexts from prehistoric to the present day. These include objects excavated from Indian Megalithic and Iron Age contexts, some going back into the first millennium BCE. More recently Datta et al ${ }^{8)}$ have published details of a furnace for the manufacture of high-tin bronze at Tilpi in western Bengal. These, together with studies revealing

\footnotetext{
* Corresponding author: E-mail: tnagae@tad.u-toyama.ac.jp DOI: http://dx.doi.org/10.2355/isijinternational.54.1172
}

continuing traditions of making high-tin bronzes, especially in Kerala of wrought and quenched high-tin bronze vessels and cymbals, suggest the regular use of unleaded bronze from very early stages of Indian prehistory. ${ }^{7,9)}$

This investigation is concerned with the bronze mirror from India where the tradition has survived in the village Aranmula in Kerala. ${ }^{10)}$ Figure 1 shows a typical Aranmula bronze mirror with bronze flame. The alloy has an exceptionally high tin content consisting almost entirely of the delta phase, which is an intermetallic compound $\left(\mathrm{Cu}_{31} \mathrm{Sn}_{8}\right)$ of composition $32.6 \%$ tin. This is an ideal alloy to be polished into a mirror due to the silvery white color and high hardness. Its high brittleness is offset by an ingenious casting and polishing process.

\section{Experimantal Procedures}

Nagae $^{11)}$ had earlier used thermographic analysis for studying the manufacture of vessels from the beta tin phase in bronze workshops in Korea, the same procedure has been followed in the present investigation of delta bronze for making mirrors.

In addition to studying the composition and the casting involving a mold cum crucible method, thermographic analysis has been employed to follow the solidification sequence by looking at the thermal profile. An infrared thermometer 
(NEC San'ei TH9100MR: hereafter "thermo tracer") was used. This device converts infrared radiations emitted from a target to electrical signals and displays them as a color thermo image. Radiation of infrared rays varies depending on materials, so it is needed to select a suitable emissivity according to the objects or the condition of their surface. It is thought that the measurement is difficult especially for metallic materials because their radiations vary extremely

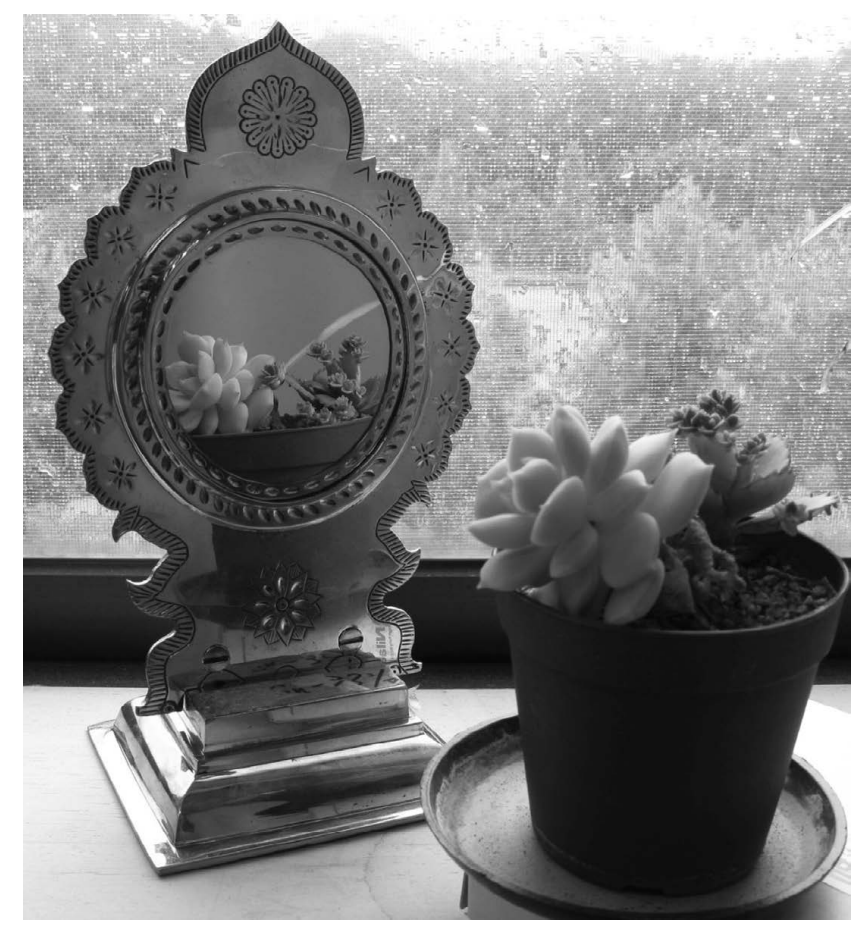

Fig. 1. A typical Aranmula bronze mirror. according to the states of their surface and their temperature. In this study, we used the emission $\varepsilon=0.77$ of copper oxide at $538^{\circ} \mathrm{C}$ to evaluate the temperature of molten metal since the surface was covered with thin oxide. And when we evaluated the mould temperature, emissivity $\varepsilon=0.95$ of clay was used. To measure temperature using a thermo tracer, one is advised to consider the noise (incident infrared rays from objects other than the target) and thus bronze products heated in a furnace are difficult to measure with this instrument.

The thermographic analysis is correlated with the actual composition, processing parameters and the resultant microstructure.

The composition of the alloy was analyzed with a Xray fluorescent spectrometer (OURSTEX corp. 100FA). Metallographic observations were made by a scanning electron microscope (Hitachi High- Technologies Corp. MiniscopeTM3000). A differential thermal analysis was carried out with Seiko Instruments Inc. TG/DTA6300.

A unique mirror making tradition survives at the village of Aranmula in Kerala state of southern India, Fig. 2. It continues for centuries practiced by traditional craftsmen known as achari. These mirrors have been prized as being part of the wedding trousseau of brides in the region. A cast unleaded high-tin bronze mirror of about $33 \%$ tin with highly or reflective properties is made using traditional clays and moulding materials. A finished mirror from Aranmula consisted of $32.5 \%$ tin, ${ }^{5)}$ approximating the composition of the pure delta intermetallic compound phase of $32.6 \%$ tin $\left(\mathrm{Cu}_{31} \mathrm{Sn}_{8}\right)$.

As seen from the $\mathrm{Cu}-\mathrm{Sn}$ phase diagram Fig. 3, such an alloy melts at a temperature of around $750^{\circ} \mathrm{C}$. There were several aspects to be understood however, in terms of the pyrometallurgical processes associated with the casting of

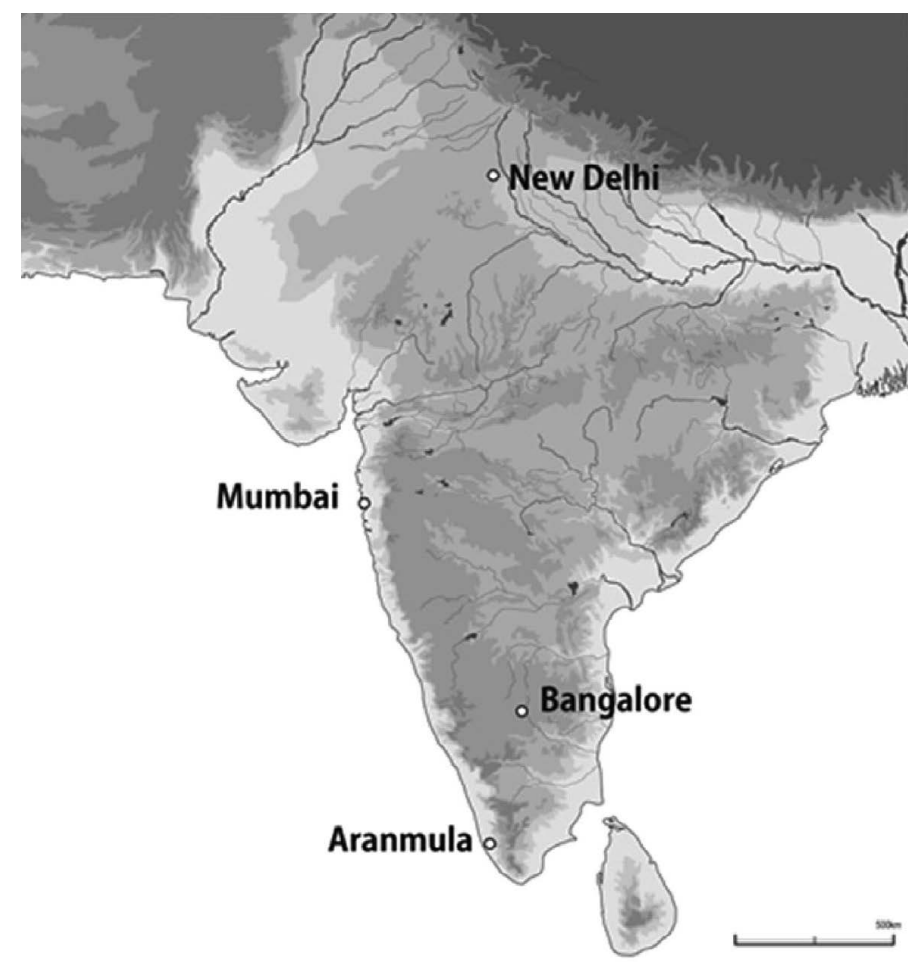

Fig. 2. Location of Aranmula in Kerala, India. 


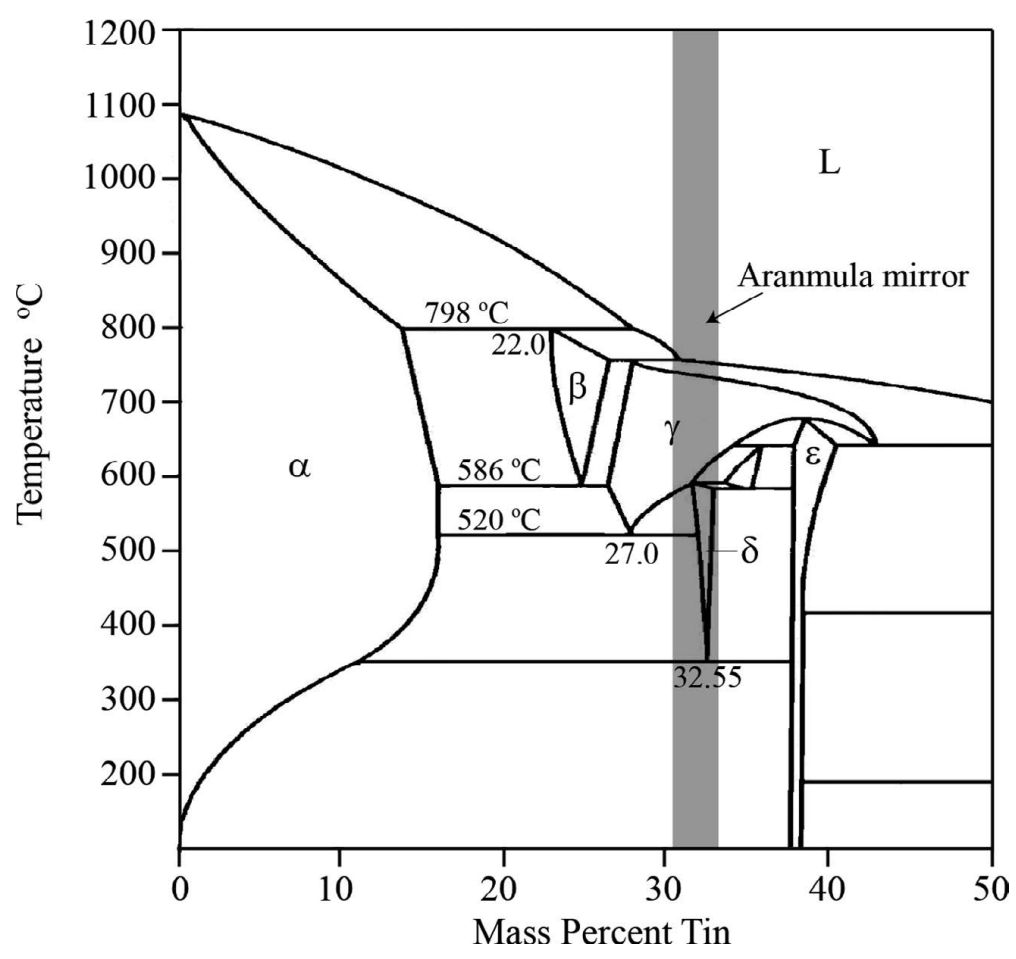

Fig. 3. $\mathrm{Cu}-\mathrm{Sn}$ phase diagram. ${ }^{12)}$

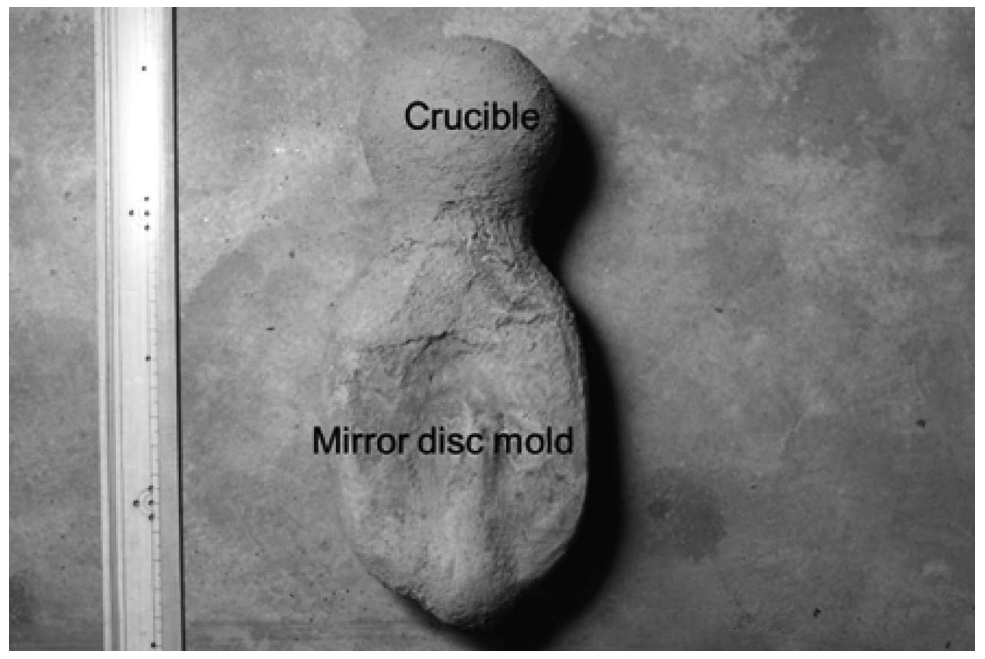

Fig. 4. Mould for making mirrors.

the alloy which the use of thermograph was thought to be able to throw more light on, for example the difference in temperature between the top part of the crucible-cum-mould which was heated face down and hence was the hottest part, and which contained the alloy, and the portion below which was the mould area into which the heated alloy would be poured by tilting it over, to form the blank. The studies revealed a considerable temperature differential in these two areas.

\subsection{Solidification Processing}

At a mirror making workshop studied in Aranmula, a cleverly made jug-shaped crucible-cum-mould of clay (Fig. 4 ) is used for casting the mirror blank of delta bronze. The lower portion consists of a two-piece clay mould which is connected to the neck, consisting of a hollow cup wherein the metal pieces to be cast are placed and sealed with clay. This closed clay crucible- cum-mould is heated in a hearth, facing neck down. Thus the metal melts in the neck, and then the jug-shaped crucible-cum-mould is tipped over so that the molten metal flows into the narrow gap between the oval two-piece mould so that it solidifies into a thin $3 \mathrm{~mm}$ oval metal blank.

\subsection{Mirror Polishing}

After breaking the mould, the cast blank is retrieved and mounted onto a wooden handle and polished over several days with hessian and velvet cloth to get a mirror finish, Fig. 5. 


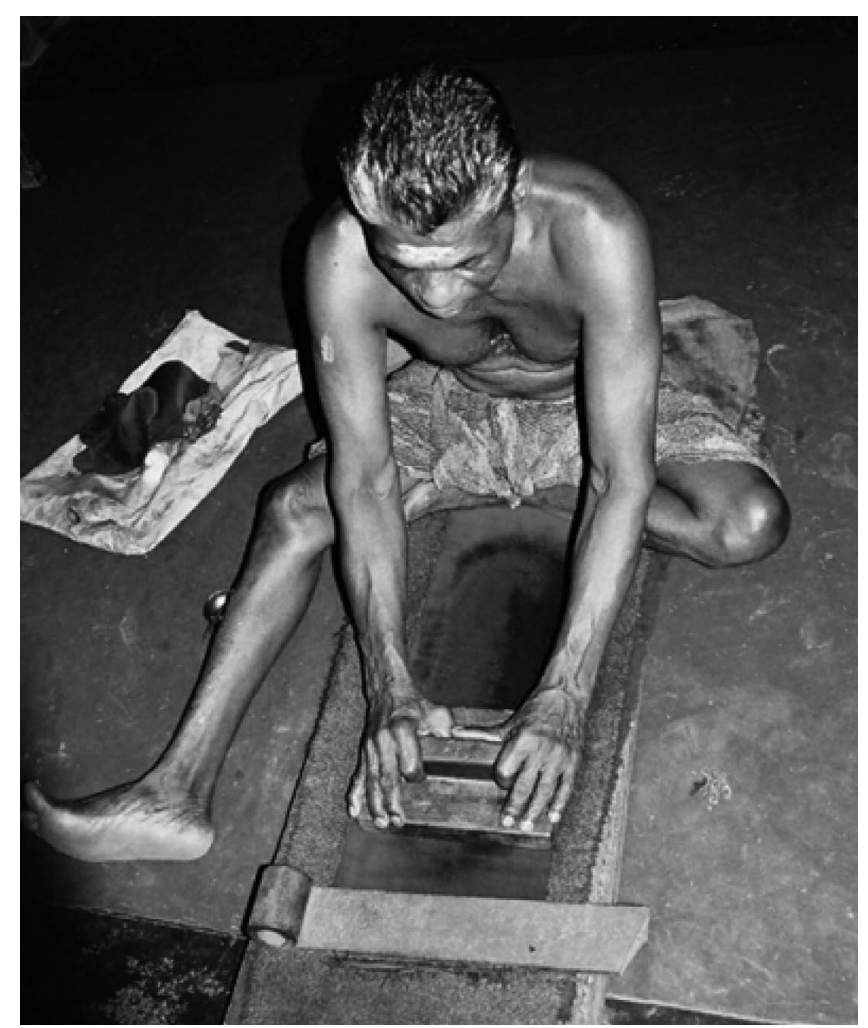

Fig. 5. Polishing the mirror.

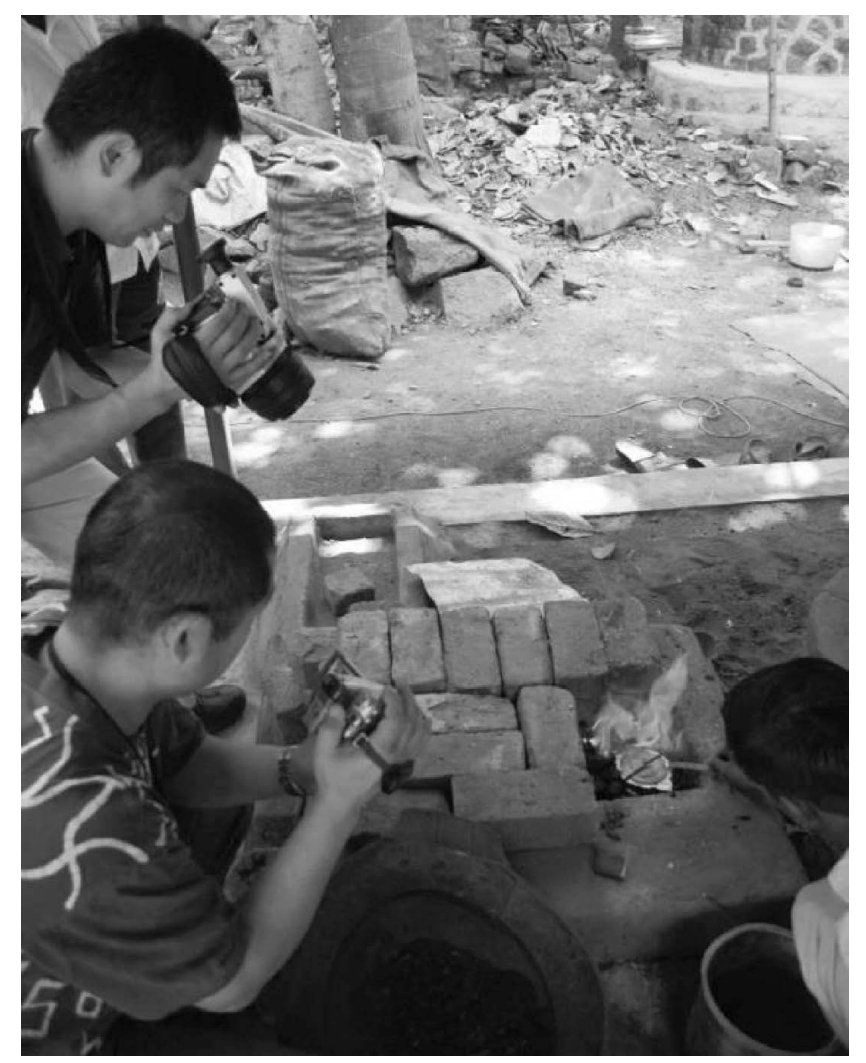

Fig. 6. Thermographic analysis.

\section{Results and Discussion}

Figure 6 shows the thermographic measurement being made with the analyzer. Figure 7 shows the thermal image. The clay mould is provided with extra insulation to with-

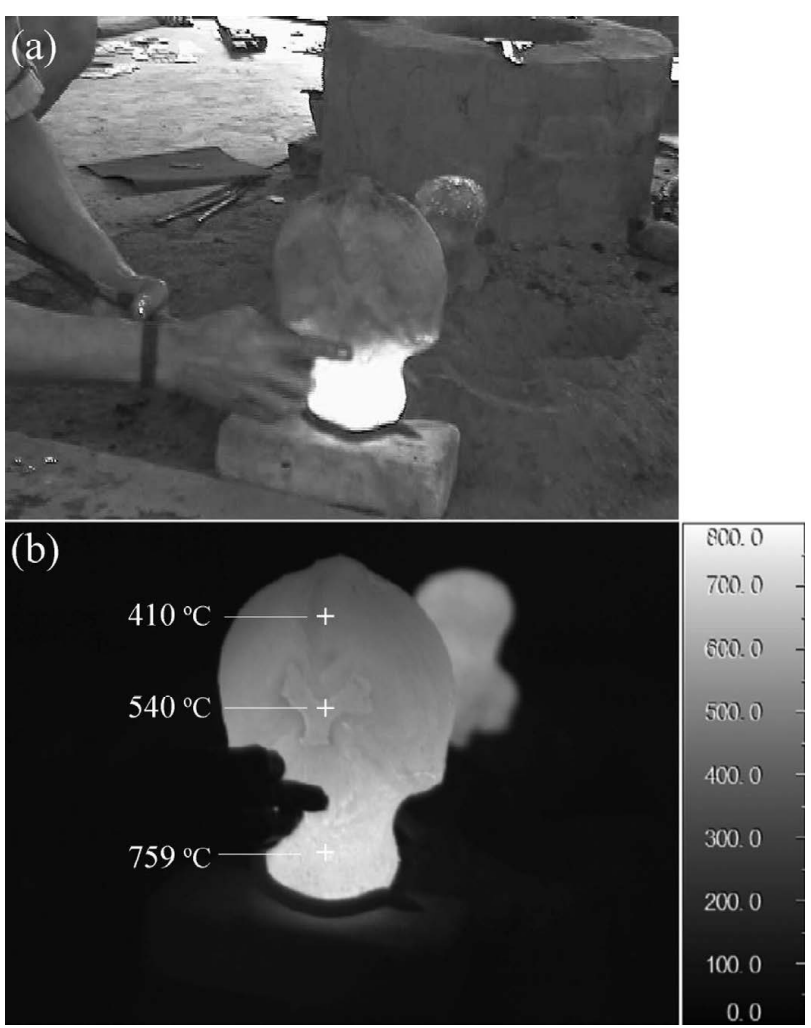

Fig. 7. Thermal image.
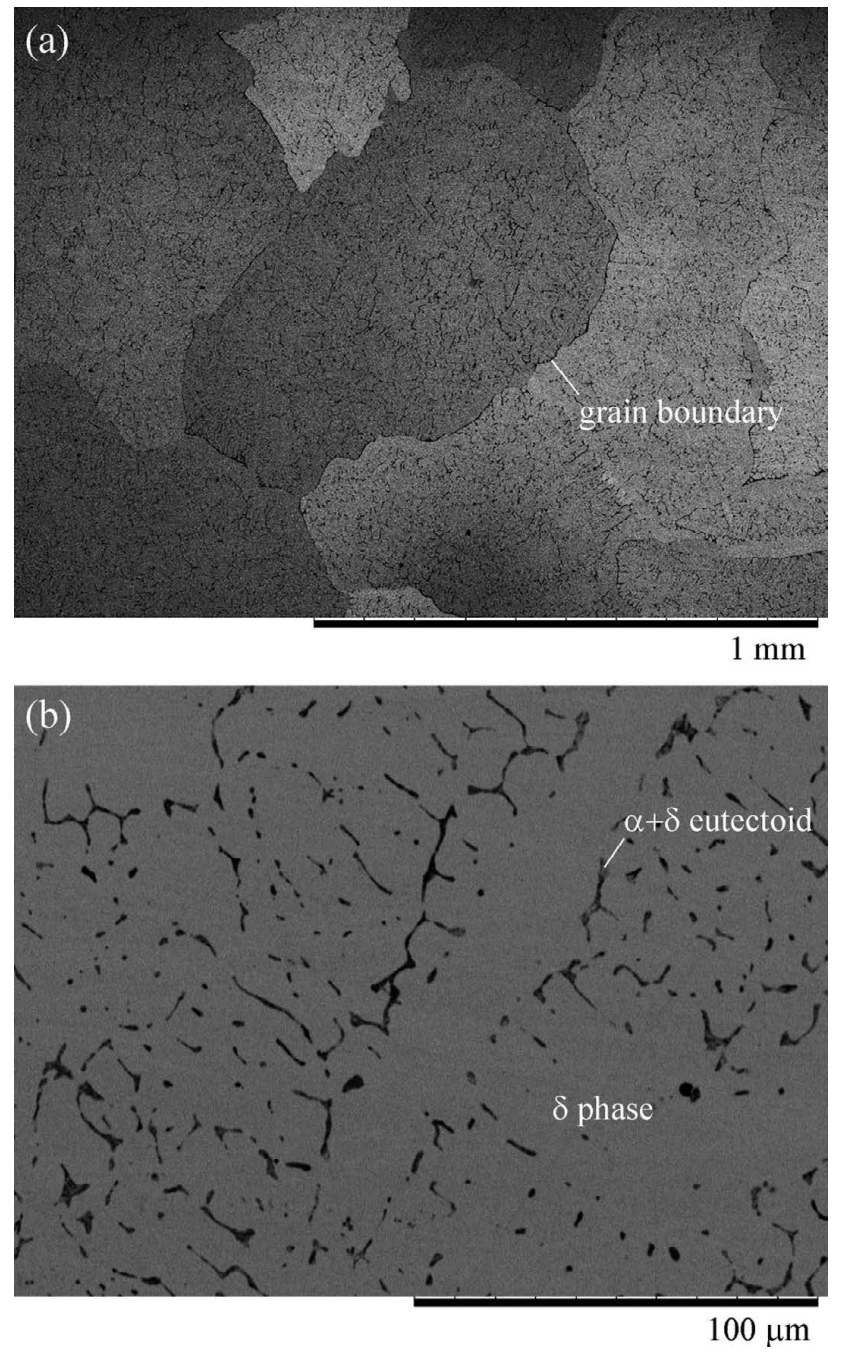

Fig. 8. Microstructure. 


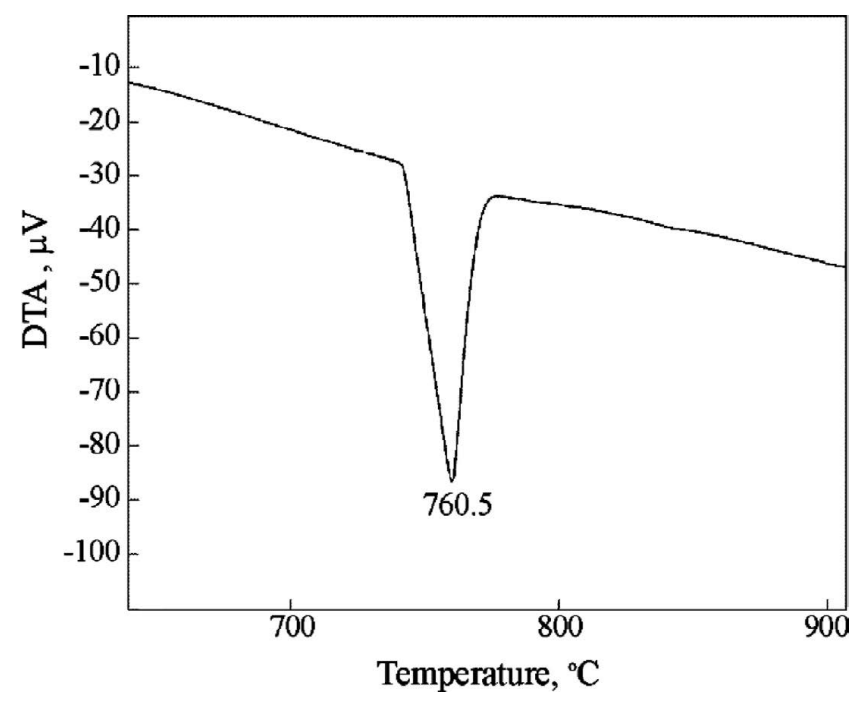

Fig. 9. DTA of a mirror fragment.

stand the temperature of the molten metal which seems to go up to at least $750^{\circ} \mathrm{C}$. A marked temperature differential is seen between the portion where the blank is and the portion where the metal is melted in the cup of the cruciblecum-mould of at least $300^{\circ} \mathrm{C}$. The mould is well designed for this closed casting process.

Figure 8 shows the microstructure of an as-cast mirror fragment. Essentially large grains of delta bronze are seen. The region between the grains shows a two phase region with minor prevalence of the eutectoid.

Figure 9 shows the differential thermal analysis curve. The melting occurs over a narrow temperature range around at least $750^{\circ} \mathrm{C}$.

\section{Conclusion}

The use of thermographic analysis is useful in throwing more light on the casting process of the delta bronze to make the mirror blank. Measurement using a thermocouple will be done in future studies to know the cooling rate of the cast metal.

\section{Acknowlegement}

This work was supported by JSPS KAKENHI Grant Number 24300300 .

\section{REFERENCES}

1) S. G. K. Pillai and A. D. Damodaran: Trans. Indian Inst. Met., 59 (2006), No. 6, 847.

2) S. G. K. Pillai, R. M. Pillai and A. D. Damodaran: JOM, 44 (1992), 38.

3) S. Srinivasan and I. Glover: Curr. Sci., 93 (2007), 35.

4) S. Srinivasan and I. Glover: J. Hist. Metall. Soc., 29 (1995), No. 2, 69.

5) S. Srinivasan: Encyclopedia of the History of Science, Technology and Medicine in Non-Western Cultures, Vol. 2, ed. by H. Selin, Springer Verlag, Berlin, (2008), 1699.

6) S. Ranganathan, S. Srinivasan and I. Glover: Asian High-tin Bronzes: Production Technology and Regional Characteristics, Japan Society for the Promotion of Science, Tokyo, (2010), 201.

7) S. Srinivasan: 50 Years of Southeast Asian Archaeology: Essays in Honour of Ian Glover, ed. by B. Bellina, O. Pryce, E. Bacus and J. W. Christie, River Books, Bangkok, (2010), 239.

8) P. Datta, P. Chattopadhyay and A. Ray: SAS Bull., Summer (2007), 13.

9) P. Craddock and D. Hook: Proc. of the 3rd Forbes Symp. at the Freer Gallery of Art, ed. by J. Douglas, P. Jett and J. Winter, Archetype Publications, UK, (2007), 75.

10) M. Mukherjee: Metalcraftsmen of India, Anthropological Survey of India, Calcutta, (1978)

11) T. Nagae: Asian High-tin Bronzes: Production Technology and Regional Characteristics, Japan Society for the Promotion of Science, Tokyo, (2010), 145.

12) T. B. Massalski: Binary Alloy Phase Diagrams, ASM International, Materials Park. OH, (1990), 1481. 